\title{
Manajemen Mutu Sekolah Melalui Pelaksanaan dan Pengawasan Program Kerja
}

\author{
Sumarto $^{1}$, Emmi Kholilah Harahap ${ }^{2}, \operatorname{Kasman}^{3}$ \\ sumarto.manajemeno@gmail.com
}

\begin{abstract}
Abstrak
Manajemen mutu sekolah diantaranya dapat dilihat dari pelaksanaan dan pengawasan program kerja yang dilaksanakan. Manajemen mutu dimulai dari perencanaan, pelaksanaan sampai kepada pengawasan sehingga dapat diketahui sampai dimana tahap pencapaiannya. Pelaksanaan program sekolah meliputi penyusunan pedoman sekolah, pembuatan struktur organisasi sekolah dan pelaksanaan kegiatan sekolah.

Pedoman sekolah meliputi kurikulum. kalender pendidikan/akademik, struktur organisasi sekolah, pembagian tugas mengajar guru, pembagian tugas tenaga kependidikan, peraturan akademik, tata tertib sekolah, kode etik sekolah, dan biaya operasional sekolah. Pada pelaksanaan kegiatan sekolah terbagi dalam delapan bidang, yaitu bidang kesiswaan, kurikulum dan pembelajaran, pendidik dan tenaga kependidikan, sarana dan prasarana, keuangan dan pembiayaan, budaya dan lingkungan, peran hubungan masayarakat dan kemitraan, serta bidang lain yang berfungsi sebagai peningkatan dan pengembangan mutu. Setelah pelaksanaan program sudah dilaksankan, kemudian proses pengawasan, untuk menngecek dan segera memperbaiki, sehingga mutu program dapat terjaga.
\end{abstract}

\section{Kata Kunci: Manajemen Mutu Sekolah, Pelaksanaan, Pengawasan}

\section{A. Pendahuluan}

Melaksanakan atau Menggerakkan erat kaitannya dengan sumber daya manusia yang pada akhirnya merupakan pusat dari semua aktivitas manajemen. Menggerakkan menawarkan tantangan dan tuntutan yang besar terhadap: nilai, sikap, harapan, kebutuhan, ambisi, serta kepuasan seseorang dan interaksi dengan orang lain dan dengan lingkungan fisik semuanya terlibat dalam upaya menggerakkan. Terry ${ }^{4}$ mengartikan Actuating is setting all members of grouf to want to achieve and to strike

\footnotetext{
${ }^{1}$ Dosen Institut Agama Islam Negeri IAIN Curup

2 Dosen STAI Ma'arif Jambi

${ }^{3}$ Dosen STAIN Madina, Panyabungan

${ }^{4}$ George R. Terry, Pengantar Manajemen, hal. 17.
} 
to achive the objective willingly and keeping with the managerial planning and organizing offorts. (pengarahan/ pengerakan adalah membuat semua anggota kelompok, agar mau bekerja secara ikhlas serta bergairah untuk mencapai tujuan sesuai dengan perencanaan dan usaha-usaha pengorganisasian).

Pimpinan selalu memberikan jalan-jalan petunjuk atau ilmu pengetahuan serta memperingatkan terhadap anggota atau karyawan guna mencapai tujuan yang sebenarnya. ${ }^{5}$ Kata actuating dalam bahasa arab diartikan dengan "al-taujih" yang juga berarti mengarahkan. ${ }^{6}$ Alquran sudah banyak menjelaskan tentang kata-kata kunci yaitu proses menggerakkan atau mengarahkan sumber daya manusia untuk mencapai tujuan bersama.

Tabsyir (memberi kabar gembira) dalam surat Al Baqarah: 213 Allah berfirman: ${ }^{7}$

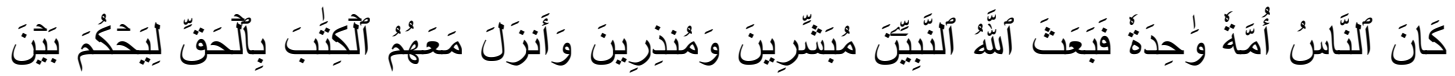

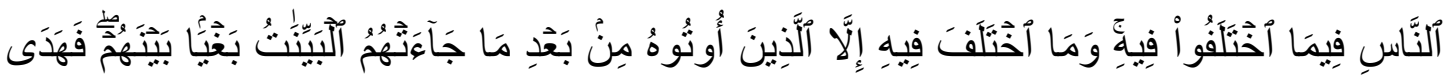

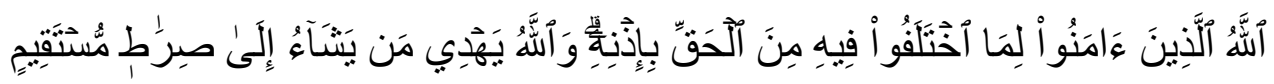

Artinya: Manusia itu adalah umat yang satu. (setelah timbul perselisihan), maka Allah mengutus para Nabi, sebagai pemberi peringatan, dan Allah menurunkan bersama mereka kitab yang benar, untuk memberi keputusan di antara manusia tentang perkara yang mereka perselisihkan. tidaklah berselisih tentang kitab itu melainkan orang yang telah didatangkan kepada mereka kitab, yaitu setelah datang kepada mereka keterangan-keterangan yang nyata, karena dengki antara mereka sendiri. Maka Allah memberi petunjuk orang-orang yang beriman kepada kebenaran tentang hal yang mereka perselisihkann itu dengan kehendak-Nya. dan Allah selalu memberi petunjuk orang yang dikehendaki-Nya kepada jalan yang lurus. (Q.S. Al Baqarah: 213).

${ }^{5}$ Sulistyorini dan Muhammad Fathurrohman, Manajemen Pendidikan Islam (Yogyakarta: Teras, 2014), hal. 51.

${ }^{6}$ Ahmad Dawud al-Muzjaji al-Asy'ari, Muqaddimah Fi al-Idarah al-Islamiyah (Jeddah: Mamlakah Al-Arabiyah al-Su'udiyah, 2000), hal. 273.

${ }^{7}$ Departemen Agama RI, Al-quran dan Terjemahannya, Al-Baqarah. 213.

VOLUME 2, NO. 2 Juli - Desember 2019 
Dalam pandangan Quraish Shihab tentang ayat di atas: sesungguhnya manusia itu memiliki karakter yang sama berupa kesiapan untuk tersesat. Sebagian mereka ada yang lebih diberi sebab-sebab untuk berbuat baik sementara yang lain memiliki kesiapan untuk tersesat. Karena itulah manusia kemudian saling berbeda. Di sinilah Allah mengutus para nabi kepada mereka untuk memberi petunjuk, memberikan kabar gembira dan peringatan. Akan tetapi yang mengambil faedah dari petunjukpetunjuk itu hanyalah orang-orang yang beriman yang telah diberi petunjuk untuk memutuskan apa yang diperselisihkan. Allah akan memberi petunjuk kepada siapa saja yang mencari kebenaran, asalkan mereka ikhlas mencarinya. ${ }^{8}$

Menurut penjelasan ayat tersebut langkah yang utama dilakukan seorang pemimpin adalah menggerakkan anggota supaya melaksanakan secara maksimal apa yang telah ditugaskan kepadanya yaitu memberi khabar gembira. Dalam kontek manajemen kabar gembira ini dapat diartikan sebagai pemberian penghargaan, sanjungan, atau motivasi sehingga bawahan dapat merasa dihargai dan punya kepercayaan dihadapan atasan serta pemberian harapan akan perbaikan tingkat kesejahteraan, yang pada akhirnya mendorong bawahan untuk melakukan pekerjaan dengan maksimal.

\section{B. Pembahasan}

\section{Pelaksanaan dalam Manajemen Mutu Sekolah}

Hal ini sejalan dengan pengertian actuating menurut Sagala, yaitu kemampuan membujuk orang-orang untuk mencapai tujuan-tujuan yang telah ditetapkan dengan penuh semangat. ${ }^{9}$ Menggerakkan suatu organisasi adalah merangsang personal organisasi melaksankan tugas-tugas dengan antusias dan kemauan yang baik untuk mencapai tujuan dengan penuh semangat.

\footnotetext{
${ }^{8}$ M. Quraish Shihab, Tafsir Al-Misbah., hal. 21.

9 Saipul Sagala, Manajemen Strategik Dalam Peningkatan Mutu Pendidikan (Bandung: Alfabeta, 2009), hal. 60.
} 
Berdasarkan Permandiknas Nomor 19 tahun 2007, dalam pelaksanaan rencana kerja sekolah mencakup: ${ }^{10}$ 1) pedoman sekolah/ madrasah; 2) struktur organisasi sekolah/ madrasah; 3) pelaksanaan kegiatana sekolah/ madrasah; 4) bidang kesiswaan; 5) bidang kurikulum dan kegiatan pembelajaran; 6) bidang pendidik dan tenaga kependidikan; 7) bidang sarana dan prasarana; 8) bidang keuangan dan pembiayaan; 9) budaya dan lingkungan sekolah/ madrasah; 10) peranserta masyarakat dan kemitraan sekolah/madrasah.

Jika dikaitakan dengan tugas kepala sekolah sebagai pengelola dalam satu lembaga pendidikan, kepala sekolah hendaknya selalu mengadakan komunikasi yang baik, hubungan kemanusiaan yang baik, kepemimpinan yang afektif, memberikan motivasi, membuat perintah serta mengadakan supervis dengan meningkatkan sikap dan moral setiap anggota kelompok. Dengan demikian, dalam actuating terdapat indikator sebagai berikut: 1) penetapan start pelaksanaan rencana kerja; 2) pemberian contoh tatacara pelaksanaan kerja dari pimpinan; 3) pemberian motivasi para pekerja untuk segera bekerja sesuai dengan tugas dan tanggung jawabnya masing-masing; 4) pengkomunikasian seluruh arah pekerjaan dengan semua unit kerja; 5) pembinaan para pekerja; 6) peningkatan mutu dan kualitas kerja; 7) pengawasan kinerja dan moralitas pekerja.

Berdasarkan penjelasan-penjelasan di atas, pelaksanaan dalam pengelolaan sekolah unggulan adalah tingkat kemampuan kepala sekolah bersama guru dan tenaga kependidikan dan personil lainnya di sekolah melakukan kegiatan pengelolaan untuk mewujudkan hasil yang direncanakan dengan menentukan sasaran, struktur tugas, wewenang, dan tanggung jawab, serta menentukan fungsi-fungsinya sehingga terlaksana pada berbagai unsur organisasi. dengan indikator: 1) terjalinnya komunikasi antara pegawai; 2) dapat melaksanakan tugas/pekerjaan dengan baik; 3) terjalinnya kerja sama; 4) kemampuan merinci pekerjaan; 6) mempunyai kemampuan membagi tugas sesuai dengan keahlian bawahan; 7) mempunyai kemampuan

${ }^{10}$ Permendiknas Nomor 19 tahun 2007

VOLUME 2, NO. 2 Juli - Desember 2019 
mendelegasikan dan mengkoordinasikan tugas kepada bawahan; 8) kemampuan membuat struktur secara lengkap.

\section{Pengawasan dalam Manajemen Mutu Sekolah}

Pengawasan merupakan proses pengamatan atau memonitor kegiatan organisasi, untuk menjamin agar semua pekejaan berjalan sesuai dengan rencana untu mencapai tujuan. Lewis et el mendefinisikan: The systematic process through which managers regulate organizational activities to make them consistenst with the expectations estabilished in plans and to help them achieve all predetermined standards of performance. ${ }^{11}$ (Pengawasan organisasi merupakan proses yang sistematis yang dengan cara ini manajer mengatur aktivitas organisasi agar aktivitas itu konsisten dengan harapan yang ditetapkan dalam rencana dan membantu aktivitas itu agar mencapai semua standar kinerja yang telah ditetapkan).

Laurie J, mendefinisikan: Management control is primarily a process for motivating and inspiring people to perfrom organization activities that will further the organizations goals. It is also a process for detecting and correcting unintentional performance errorsand intentional irregularities, such as theft or misuse of resources. ${ }^{12}$ Dengan demikaian (pengawasan manajemen merupakan proses untuk memotivasi dan menginspirasi orang untuk menjalankan aktivitas organisasi yang akan memajukan tujuan organisasi. Pengawasan juga merupakan proses untuk mendeteksi dan mengoreksi kesalahan kinerja yang tidak disengaja, seperti pencurian atau penyalahgunaan terhadap sumber daya).

Terry merumuskan pengawasan atau pengendalian sebagai suatu usaha untuk meneliti kegiatan-kegiatan yang telah dilaksanakan. Pengawasan berorientasi pada

${ }^{11}$ Lewis. Pamela, S. et al. Management: Challenges For Tumorrw'S Leaders (USA: Thomas SouthWestern, 2007), hal. 405.

${ }^{12}$ Mullins, Laurie J, Management and Organizational Behaviour (USA: Pearson Prentice Hall, 2005), hal.832.

VOLUME 2, NO. 2 Juli - Desember 2019 
objek yang dituju dan merupakan alat untuk menyuruh orang-orang bekerja menuju sasaran yang akan dicapai. ${ }^{13}$

Sedangkan Maisah menjelaskan: pengawsan adalah mengadakan pengamatan secara terus menerus, merekam, memberi penjelasan dan petunjuk, artinya memberi pembinaan dan pelurusan terhdap berbagai ketidak tepatan dan kesalahan. Pengawasan merupakan kunci keberhasilan manajemen. ${ }^{14}$ Sedangkan Sulistiyorini, menjelaskan: kontrol atau pengawasan adalah kegiatan mengukur efektifitas kerja personil dan tingkat efisiensi penggunaan metode dan alat tertentu dalam usaha mencapai tujuan, yang befungsi mengupayakan penyesuaian antara rencana yang telah disusun dengan pelaksanaan atau hasil yang benar-benar dicapai. ${ }^{15}$

Begitu pentingnya pengawasan dalam proses manajemen untuk mendukung aktivitas organisasi dalam mencapai tujuan, pengendalian harus mendapat perhatian para pengambil keputusan dan kebijakan (pengelola/manejer). Hal ini ditegaskan Hitt: Regulation of activites and behaviors within organizational adjustment or conformity to specifications or objectives. ${ }^{16}$ (Pengawasan merupakan proses memantau kinerja dan mengambil tindakan untuk memastikan hasil yang dikehendaki). Dalam Alquran pengawasan bersifat transendental, jadi dengan begitu akan muncul inner dicipline (tertib diri dari dalam). Itulah sebabnya di zaman generasi Islam pertama, motivasi kerja mereka hanyalah Allah kendatipun dalam halhal keduniawian yang saat ini dinilai cenderung sekuler sekalipun. ${ }^{17}$

Mengenai fungsi pengawasan, Allah SWT berfirman di dalam Alquran Asy Syuura ayat:48 sebagai berikut: ${ }^{18}$

\footnotetext{
${ }^{13}$ George R. Terry, Op.Cit., hal.166.

${ }^{14}$ Maisah, Manajemen Pendidikan (Ciputat: Gunung Persada Press Group, 2013), hal. 143.

${ }^{15}$ Sulistiyorini, Op. Cit., hal. 58.

${ }^{16}$ Hitt Michael A, J. Steward Black, Management (New Jersey: Pearson Education, Inc, 2012), hal. 388.

${ }^{17}$ Syafiie, Al-Qur'an Dan Ilmu Administrasi (Jakrta : Rineka Cipta, 2008), hal. 66.

${ }^{18}$ Departemen Agama RI, Al-quran dan Terjemahannya, Asy Syuraa. 48.
}

VOLUME 2, NO. 2 Juli - Desember 2019 


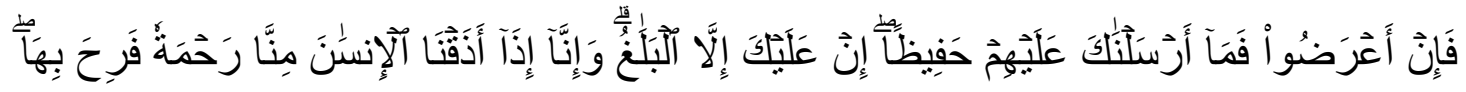

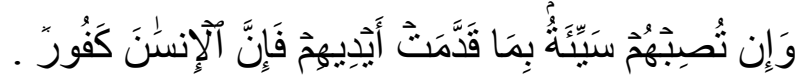

Artinya: Jika mereka berpaling Maka Kami tidak mengutus kamu sebagai Pengawas bagi mereka. kewajibanmu tidak lain hanyalah menyampaikan (risalah). Sesungguhnya apabila Kami merasakan kepada manusia sesuatu rahmat dari Kami Dia bergembira ria karena rahmat itu. dan jika mereka ditimpa kesusahan disebabkan perbuatan tangan mereka sendiri (niscaya mereka ingkar) karena Sesungguhnya manusia itu Amat ingkar (kepada nikmat). (QS. As Syuura: 48).

Contoh pengawasan dari fungsi manajemen dapat dijumpai dalam Hadits yang diriwayatkan oleh Imam Bukhari sebagai berikut:

Al Bukhari Muslim meriwayatkan dari Ibnu „Abbas, ia berkata: “Suatu malam aku menginap di rumah bibiku, Maimunah. Setelah beberap saat malam lewat, Nabi bangun untuk menunaikan shalat. Beliau melakukan wudhu ringan sekali (dengan air yang sedikit) dan kemudian shalat. Maka, aku bangun dan berwudhu' seperti wudhu' Beliau. Aku menghampiri Beliau dan berdiri di sebelah kirinya. Beliau memutarku ke arah sebelah kanannya dan meneruskan shalatnya sesuai yang dikehendaki Allah (HR. Bukhari). ${ }^{19}$

Berdasrkan riwayat dalam Haditst di atas dapat ditemukan upaya pengawasan Nabi Muhammad SAW terhadap Ibnu Abbas yang melakukan kesalahan karena berdiri di sisi kiri Beliau saat menjadi makmum dalam shalat bersama Beliau. Karena seorang makmum harus berada di sebelah kanan imam, jika ia sendirian bersama imam. Beliau SAW. tidak membiarkan kekeliruan Ibnu Abbas dengan dalih umurnya yang masih dini, namun Beliau SAW tetap mengoreksinya dengan mengalihkan posisinya ke kanan Beliau SAW. Dalam melakukan pengawasan, beliau langsung memberi arahan dan bimbingan yang benar.

Dapat disimpulkan pengawasan atau pengendalian adalah suatu kegiatan untuk mengukur dan meneliti juga mengoreksi pelaksanaan suatu rencana yang telah disusun agar berjalan dengan efektif. Maka pengawasan atau control yang berorientasi pada peningkatan mutu adalah sistem control yang kegiatannya sebagai

${ }^{19}$ Shahih Bukhari, Kitab Adzan, Bab Wudhu`Anak-Anak ... no. Hadits. 859.

VOLUME 2, NO. 2 Juli - Desember 2019 
tonggak dasar peningkatan mutu dan pelaksanaan sistem tersebut berorientasi pada kaidah-kaidah mutu.

\section{Proses Pengawasan}

Beberapa unsur yang perlu diketahui dalam proses pengawasan atau pengendalian, antara lain: 1) adanya proses dalam menetapkan pekerjaan yang telah dan akan di laksanakan; 2) merupakan alat untuk menyuruh orang bekerja menuju sasaran yang akan dicapai; 3) memonitor, menilai dan mengoreksi pelaksanaan pekerjaan; 4) menghindari dan memperbaiki kesalah, penyimpangan dan penyalahgunaan; 5) mengukur tingkat efektifitas dan efisiensi kerja; 6) berorientasi pada peningkatan mutu dan sebagai alat feedback.

Disamping itu diperoleh beberapa hal yang esensial tentang pengawasan: 1) pengawasan merupakan proses yang sitematis dalam pengertian yang bersifat mengatur, memotivasi, menginspirasi, mendeteksi, atau mengoreksi; 2) tujuan pengawasan adalah agar activitas selaras atau konsisten dengan harapan-harapan yang ditetapkan dalam perencanaan, atau agar mencapai semua standar kinerja yang telah ditetapkan; 3) pengawasan juga berfungsi untuk mendeteksi dan mengoreksi kesalahan atau penyimpangan baik disengaja maupun tidak.

Prinsip-prinsip pengawanasan menurut Marno mengemukakan: 1) prinsip tercapainya tujuan, yaitu menghindari terjadinya penyimpangan; 2) prinsip efisiensi pengawasan, yaitu untuk menghindari deviasi-deviasi dari perencanaan agar tidak menimbulkan hal-hal diluar dugaan; 3) perisip tanggung jawab, yaitu pengawasan dapat dilaksanakan apabila manajer dapat bertanggung jawab penuh terhadap pelaksanaan rencana; 4) perisip pengawasan terhadap masa depan, yaitu pengawasan yang efektif harus ditunjukkan ke arah pencegahan, penyimpangan perencanaan yang akan terjadi pada waktu sekarang atau masa yang akan datang; 5) prinsip pengawasan langsung, yaitu manejer mengusahakan adanya bawahan yang berkualitas baik; 6) prinsip refleksi perencanaan, yaitu pengawasan disusun dengan baik sehingga mencerminkan karakter dan susunan perencanan; 7) prinsip penyesuaian dengan 
organisasi, yaitu pegawasan harus sesuai dengan struktur organisasi; 8) prinsip pengawasa individu, yaitu tehnik pengendalian harus sesuai dengan kebutuhan manajer; 9) prinsip standart, yaitu mempunyai tolak ukur; 10) prinsip pengawasan strategi, yaitu ditentukan dengan faktor-faktor yang strategi; 11) prinsip perkecualian, yaitu perkecualian dapat dilaksanakan jika ada perubahan; 12) prinsip pengawasan fleksibel, yaitu pengawasan harus luas; 13) prinsip peninjauan kembali, yaitu sistem control harus ditinjau berulang-ulang; 14) prinsip tindakan, yaitu pengawasan dapat dilakukan apabila ada ukuran-ukuran rencana organisasi, staffing dan directing. ${ }^{20}$

Sedangkan dalam dunia pendidikan evaluasi merupakan kegiatan pengendalian, penjaminan dan penetapan mutu pendidikan terhadap berbagai komponen pada setiap jalur, jenjang dan jenis pendidikan sebagai bentuk pertanggung jawaban penyelenggaraan pendidikan.

Bloom et al menyatakan, Evaluation is defined as the making of judgments about the value, for some purpose, of ideas, works, solutionsmethods, material, etc. It involves the use of criteria as well as standards for appraising the extent to which particulars are accurate, effective, economical, or satisfying. ${ }^{21}$ Evaluasi didefinisikan sebagai pembuatan penilaian tentang nilai, untuk beberapa tujuan, ide, bekerja, solusi, metode, materi, dll Ini melibatkan penggunaan kriteria sebagai serta standar untuk menilai sejauh mana khusus akurat, efektif, ekonomis, atau memuaskan.

Dalam pendidikan Islam, evaluasi itu juga cukup penting. Hal ini sesuai dengan ungkapan sayyidina Umar R.A. ${ }^{22}$

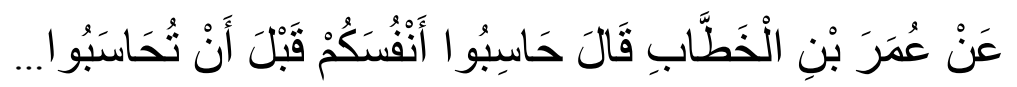

Dari Umar ibn al-Khaththab, dia berkata: koreksilah dirimu sekalian sebelum kamu sekalian dikoreksi. Perkataan tersebut apabila dipahami nampaknya menunjukkan adanya evaluasi bagi siapapun, baik itu personal maupun berupa

${ }^{20}$ Marno, Op. Cit., hal. 25-26.

${ }^{21}$ Benjamin Bloom, et al. Taxonomy of Educational Objectives The Classification of Educational Goal Handbook I Cognitive Domain (New York: David Mc. Lay Company. 2011), hal. 185.

${ }^{22}$ Muhammad bin Isa al-Turmudzi, Sunan Turmudzi, juz 8 (Mauqi'u al-Islam: Dalam Software Maktabah Syamilah, tt), hal. 499. 
organisasi. Maka seorang manajer harus selalu ber-musahabah dalam segala kegiatan yang ia putuskan dan lakukan, apakah kegiatan tersebut telah mampu mencapai tujuan atau tidak. Pada bidang pendidikan, kita dapat melakukan evaluasi terhadap kurikulum baru, suatu kebijakan pendidikan, sumber belajar tertentu, atau etos kerja guru. Berdasarkan beberapa pengertian tersebut, dapat disimpulkan evaluasi lebih dekat kepada sebuah proses pengumpulan data dan fakta dengan memanfaatkan sarana pengukuran serta penilaian untuk memberikan informasi dalam upaya pengambilan keputusan, dan dilakukan secara terus menerus atau berkelanjutan.

Menurut Permandiknas Nomor 19 tahun 2007, yang dimaksud evaluasi sekolah adalah evaluasi diri terhadap kinerja sekolah dengan menetapkan priototas indikator untuk mengukur, menilai, kinerja, dan melakukan perbaikan dalam rangkan pelaksanaan standar nasional pendidikan. Dengan melaksankan: a) evaluasi proses pembelajaran secara periodik sekurang-kurangnya dua kali dalam setahun, pada akhir semester akademik; b) evaluasi program kerja tahunan secara periodik sekurangkurangnya satu kali dalam setahun, pada akhir tahuan anggaran sekolah; c) evaluasi sekolah dilaksankan secara periodik berdasarkan pada data informasi yang sah. ${ }^{23}$

Tahap Proses Pengawasan

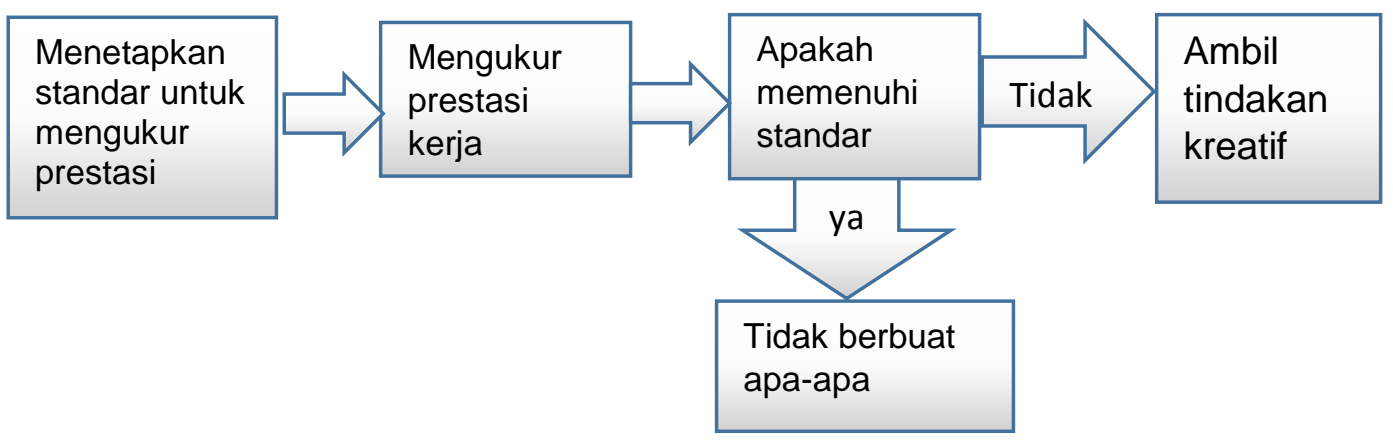

Sumber: Muhammad Fathurrohman. ${ }^{24}$

${ }^{23}$ Permendiknas Nomor 19 tahun 2007.

${ }^{24}$ Sulistyorini, dan Muhammad Fathurrohman, Op. Cit., hal. 63.

VOLUME 2, NO. 2 Juli - Desember 2019 
Tahapan dalam pegawasan sekolah dapat dilakukan melalui tahapan-tahapan yang telah ditentukan berdasarkan perencanaan yang telah disusun sebelumnya. Seorang pengelola/kepala sekolah dapat melakukan fungsi pegawasan/pengendalian dengan baik, jika mengetahui dengan jelas proses pengawasan tersebut. Tahapantahapan pengawasan adalah: 1) menentukan standar-standar atau dasar untuk mengawasi yang dapat dijadikan sebagai pedoman untuk mengukur kerja dan prestasi guru dan pegawai lainnya; 2) mengukur pelaksanaan kerja guru, dan pegawai lainnya pada satu sekolah; 3) membandingkan pelaksanaan dengan standar yang ada dan menentukan deviasi-deviasi bila terjadi atau ada; 4) melakukan tindakan-tindakan, perbaikan-perbaikan jika ada penyimpangan agar pelaksanaan dan tujuan sesuai dengan rencan. Dengan demikian, stiap kegiatan pendidikan di sekolah harus memilki perencanaan yang jelas dan realistis, pengorganisasian yang efektif dan efisien, serta pelaksanaan dan pemotivasian terhadap seluruh personil sekolah untuk selalu dapat meningkatkan kualitas kinerjanya.

Dapat disimpulkan pengawasan dan evaluasi adalah merupakan suatu kegiatan berkelanjutan secara terus-menerus yang berusaha untuk mengawasi/mengendalikan agar pelaksanaan dapat berjalan sesuai dengan tujuan yang telah ditetapkan. Idikator pengawasan dan evaluasi adalah: 1) memiliki kemampuan untuk mengawasi/mengendalikan; 2) mempunyai komitmen untuk perbaikan; 3) dapat dijadikan alat untuk memerintah/menyuruh bawahan untuk bekerja; 4) menjadikan tolak ukur keberhasil/pencapaian; 5) dapat menjalin hubungan kerja sama demi perbaikan.

\section{Kesimpulan}

Pelaksanaan atau Penggerakkan tersebut adalah motivasi, yang dapat mendorong seseorang untuk untuk melakukan kegiatan. Karena motivasi dapat mempegaruhi prestasi seseorang dalam melakukan kegiatan. Hal yang perlu diperhatikan dalam penggerakkan (actuating) adalah bahwa seorang bawahan akan 
termotivasi unuk mengerjakan sesuatu jika: 1) merasa yakin akan mampu mengerjakan; 2) yakin jika pekerjaan tersebut akan bermanfaat bagi dirinya; 3) tidak sedang dibebani problem pribadi atau tugas lain yang lebih penting, yang mendesak; 5) menciptakan hubungan yang harmonis terhadap sesama.

Proses pengawasan dapat melibatkan beberapa elemen yaitu :1) menerapkan standar kinerja; 2) mengukur kinerja; 3) membandingkan untuk kerja dengan standar yang ditetapkan; 4) mengambil tindakan korektif saat terdeteksi penyimpangan. ${ }^{25}$ Tujuan pengawasan menurut konsep sistem adalah membantu mempertahankan hasil atau output yang sesuai dengan syarat-syarat sistem. Sedangkan berdasarkan definisi di atas, tujuan pengawasan adalah penilaian pelaksanaan dan penyesuaian dengan perencanaan yang digunakan sebagai feedback dalam perencanaan berikutnya yang berorientasi pada peningkatan mutu.

\section{Daftar Pustaka}

Ahmad Dawud al-Muzjaji al-Asy'ari, Muqaddimah Fi al-Idarah al-Islamiyah (Jeddah: Mamlakah Al-Arabiyah al-Su'udiyah, 2000).

Benjamin Bloom, et al. Taxonomy of Educational Objectives The Classification of Educational Goal Handbook I Cognitive Domain (New York: David Mc. Lay Company. 2011).

Departemen Agama RI, Al-quran dan Terjemahannya, Al-Baqarah.

Departemen Agama RI, Al-quran dan Terjemahannya, Asy Syuraa.

Engkoswara dan Aan Komariah, Administrasi Pendidikan (Bandung: ALFABETA, 2012).

George R. Terry, Pengantar Manajemen.

Hitt Michael A, J. Steward Black, Management (New Jersey: Pearson Education, Inc, 2012).

Lewis. Pamela, S. et al. Management: Challenges For Tumorrw'S Leaders (USA: Thomas South-Western, 2007).

M. Quraish Shihab, Tafsir Al-Misbah.

Maisah, Manajemen Pendidikan (Ciputat: Gunung Persada Press Group, 2013).

Muhammad bin Isa al-Turmudzi, Sunan Turmudzi, juz 8 (Mauqi'u al-Islam: Dalam Software Maktabah Syamilah, tt).

${ }^{25}$ Engkoswara dan Aan Komariah, Administrasi Pendidikan (Bandung: ALFABETA, 2012), hal. 96.

VOLUME 2, NO. 2 Juli - Desember 2019 
Mullins, Laurie J, Management and Organizational Behaviour (USA: Pearson Prentice Hall, 2005).

Permendiknas Nomor 19 tahun 2007

Saipul Sagala, Manajemen Strategik Dalam Peningkatan Mutu Pendidikan (Bandung: Alfabeta, 2009).

Shahih Bukhari, Kitab Adzan, Bab Wudhu`Anak-Anak ... no. Hadits. 859.

Sulistyorini dan Muhammad Fathurrohman, Manajemen Pendidikan Islam (Yogyakarta: Teras, 2014).

Syafiie, Al-Qur'an Dan Ilmu Administrasi (Jakrta : Rineka Cipta, 2008). 